\title{
A Comparative Analysis of China's Subtitling Models between Official Film Studios and Fansubs
}

\author{
Jiang Xuelong \\ Northwest Minzu University \\ Lanzhou, China
}

\begin{abstract}
This paper aims to introduce, compare and analyze the subtitling mechanisms and procedures of both China's official film studios and fansubs. By comparison, the author finds that both of them have advantages and disadvantages. After analyzing the disadvantages of coexistence, four problems of lack of staff, low subtitling payment, low subtitler's status and nonunified subtitling standards are introduced, and four corresponding suggestions are proposed to improve the subtitling system and process of official and voluntary organizations, thus promoting the development of film subtitling in China.
\end{abstract}

Keywords-Subtitling model; Comparative analysis; Official film studio; Fansub

\section{INTRODUCTION}

In 2012, official and web-based translations of Man in Black III were heated discussed, some audiences believed that the official film subtitling version was better, some considered the version of fansub was subtitled better, and others held that both of their translations had errors. It is insufficient only to judge their translation qualities or discuss this phenomenon, we should explore their deeper reasons through this surface phenomenon, reflect the existing problems of China's both official and web-based subtitling systems and procedures, put forward corresponding suggestions, and take some necessary measures to improve this kind of situation, so as to make our film industry develop better and faster.

\section{CHINA'S OFFICIAL SUBTITLING SYSTEM AND PROCEDURE}

\section{A. Subtitling System}

In 2004, Hu zhifeng, a professor of Communication University of China, clearly illustrated the constituents of China's official subtitling and dubbing system, which includes subtitling and dubbing staff, institutions and official sectors[1]. However, after nearly ten years of development, some changes have been taken place in the official film subtitling industry. For example, in 2012, the subtitling department of China Film Group (CFG) was renamed as Beijing Film Subtitling Studio which is an independent studio instead of a official department. In addition, Hu's system actually comprises the subtitling and the dubbing two systems. But only the subtitling system is discussed specifically in this paper. Hence based on Hu's subtitling and dubbing system, the figure of China's official film subtitling system (abbr. COFSS ) is revised as follows:

This research was financially supported by 2017 Scientific Research Funds for Universities in Gansu Province (2017B-86) and 2017 Fundamental Research Funds for Central Universities (31920170050).

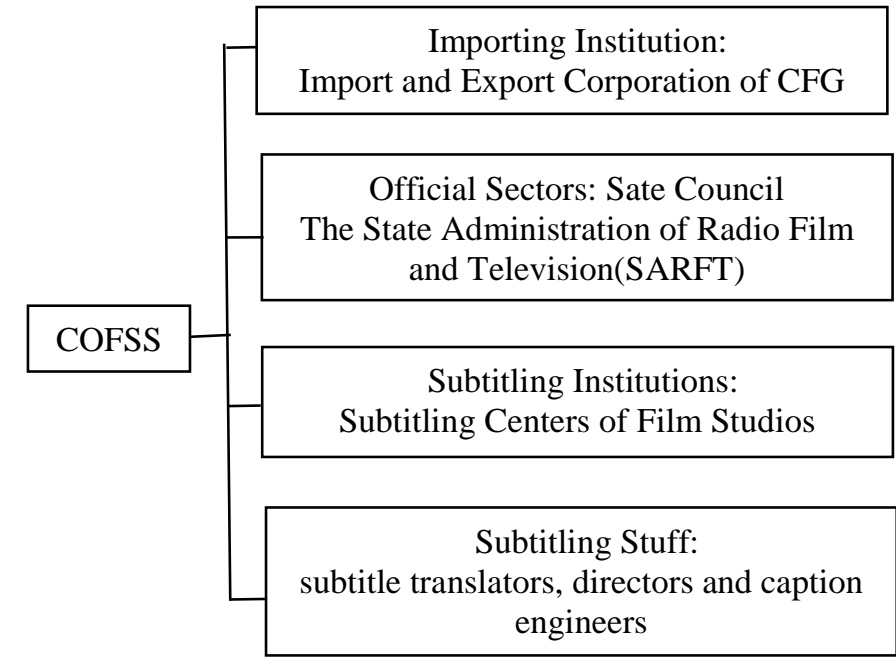

Fig. 1 China's Official Film Subtitling System

From the above figure, we can know that the official film subtitling system consists of four constituents, of which the importing institution is mainly responsible for importing, exporting and distributing films, official sectors are in charge of making related policies and supervising related institutions, the principal duty of subtitling institutions is to formulate industry regulations, and subtitle translators, directors and caption engineers take charge of subtitle translating, film directing, and subtitle editing respectively.

\section{B. Subtitling Procedure}

There are only four official subtitling and dubbing agencies in China: Changchun Film Studio, Shanghai Film Studio, Beijing Film Studio, and PLA's August First Film Studio. They have an extremely glorious history and have a great influence on generations after generations in the last century. They share the same subtitling procedure: step one is film importing and reviewing for the first time, specifically speaking, China Film Import and Export Corporation of CFG gets a sample film from the film producer and sends it to SARFT for examination; step two is film distributing. The film will be distributed to one of the four studios after passing SARFT's first reviewing. Step three is film subtitling, the studio assigns translators, directors and subtitlers to cooperate to subtitle the film, and two film versions: the original subtitle version and the Chinese dubbing version are produced. The last step is the final review. After being checked and approved by SARFT for the second time, the two versions are shown in 
cinemas[2]. The subtitling procedure is mapped in the following figure.

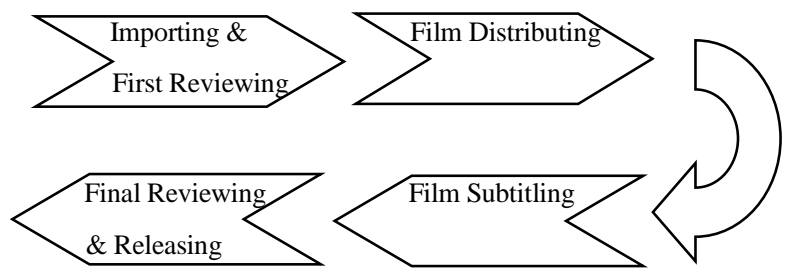

Fig. 2 China's Official Film Subtitling Procedure

The first time reviewing is to determine whether the film will be imported. And CFG is responsible for film importing and distributing. When CFG distributed the film to one film studio, the studio should legally purchase the film rights in accordance with the provisions of economic law, so that the subtitled film can be released in China legally. Before the film releasing, subtitlers, and subtitling agencies play the most important role, for they determine how lines are translated and whether shots, plots and images need to be edited. After the film is completed subtitling, it is subject to re-examination by the government department (mainly the SARFT, and the State Council don't involve the examination of subtitled film). At this time, not only the film subtitling level but also its subtitling content and plot will be examined, but comparatively speaking, the ideology of film subtitles, instead of their artistry, are paid more attention. As long as the subtitles are in keeping with China's ideology and conform to Chinese customs, the film will get approved.

\section{SUBTITLING MECHANISM AND PROCEDURE OF FANSUB}

Fansub, as a kind of voluntary and non-profit individual organization, refers to a group of fans who attach foreign films with local subtitles according to their own interests. The word "fansub" is blended from "fan + subtitling". And its birth is due to four reasons: (1) popularity of the Internet; (2) massive release of good dramas, animations and movies from foreign countries, especially from Europe and the United States; (3) long time of importing foreign films and tedious process of examination and approval by the film and television institutions that have the importing right, such as CCTV; (4) low foreign language level of Chinese people.

After fansub perfects its translation process and improves its translating skills, its popularity will gradually increase, and it will continue to grow and develop into BBS and even become a film and television portal website. The established BBS size not only depends on the size of fansub itself, but also depends upon the numbers of BBS user registration, BBS resource download, post number, click-on and so on. So Film and TV BBS is the virtual place where fansubbers and users can communicate with each other. At present, there are four most influential fansubs in China: Yidianyuan (YDY), Fengruan (1000fr), Ragbear and Renrenyingshi (YYets). In general, YDY prefers subtitling crime shows, 1000fr tends to subtitle medical dramas, YYets focuses on science fiction and history dramas [3], while Ragbear is good at British films, especially the ones adapted from classical novels on BBC.

\section{A. Subtitling Procedure}

Since 2001, fansubs have been popular for about 18 years, and same as the official subtitling institutions, they also have developed a wonderfully complete subtitling procedure as following:

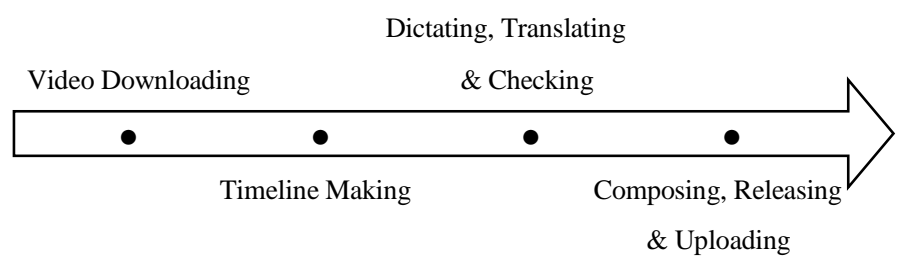

Fig. 3 Subtitling Procedure of Fansubs

According to the above subtitling procedure, the first step is to find video sources and download them. In China, the videos are mainly provided by a mysterious organization-Oday whose members and structure are unknown to outsiders. As soon as the films are released, Oday will record them for global film lovers for free and puts them on the server for everyone to download. And then domestic fansubbers can obtain these sources via FTP or BT. If the source videos are without source language subtitles, in order to reduce the workload of later translation, the fansubbers usually obtain the subtitles through CC subtitle which is a pattern of humanized setting of English subtitles for hearing impaired people in the United States. In the fansub, the team that gets the film source and part of the subtitles is called the "Transporting Team". After the contributions of the transporting team, the next step needs the efforts of Timeline Making Team. They take charge of removing ads from the source film, correcting the timeline of CC subtitles, and so on. Typically, the timeline for an episode of a TV series takes them about two to three hours to make, and longer episodes take longer time. The source with the timeline will be then handed over to several members of the Dictating and Translating Team to check and translate them. After completion of the first draft of subtitle translation, it will be transferred to the Proofreading Team, who will correct the translation errors, unify the translation style, and re-check the timeline[4]. Meanwhile, the Proofreading Team also needs to modify some expressions that are not audience-friendly. After proofreading, the subtitles will be uploaded online for free by the technical staff of Composing and Uploading Team for everyone to download. Due to domestic users' dislike to download subtitles alone, the technical staff will also compose the subtitles into the video, and then upload and release the composed video.

Above all, subtitling procedure of fansubs mainly contains four steps, i.e., Video Downloading, Timeline Making, Dictating, Translating and Proofreading and Subtitle Releasing, Movie Composing and Uploading.

\section{B. Subtitling Mechanism}

On the basis of the above procedure, it can be said that a complete fansub group generally includes five sections: Transporting Team (TT), Timeline Making Team (TMT), Dictating and Translating Team (DTT), Proofreading Team (PT) and Composing and Uploading Team (CUT). Hence, the 
subtitling mechanism of fansubs (abbr. SMF) can be mapped as the figure below:

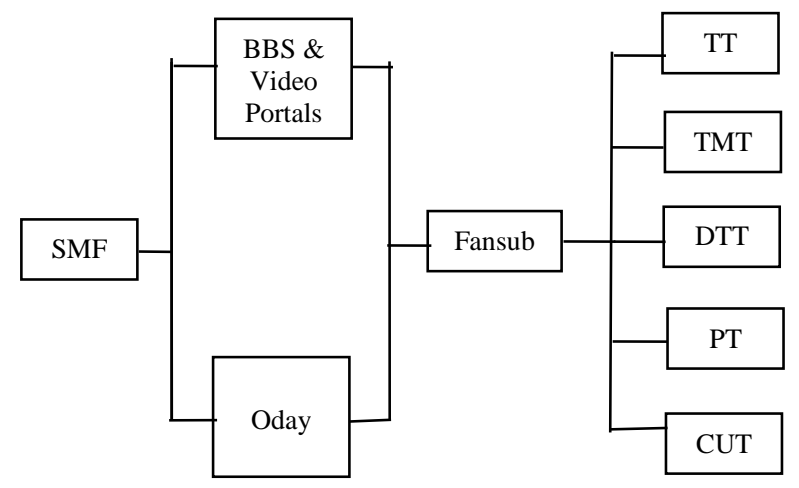

Fig. 4 Subtitling Mechanism of Fansubs

\section{COMPARATIVE ANALYSIS ON TWO SUBTITLING MECHANISMS AND PROCEDURES}

After comparing the above four figures, we can conclude that both the official and web-based subtitling mechanisms and procedures have their own advantages and disadvantages. The procedure of fansub is apparently more detailed and matured, while the official procedure is with great advantages in the film importing and examining, though it has some defects in the subtitle translation.

\section{A. Comparative Analysis on Subtitling Mechanisms}

The fansub is subdivided into five teams whose duties are clear and reasonable, whereas in the official subtitling system, only the director, subtitler, and caption engineer are responsible for the subtitle translation, so the subtitling work of a film is usually completed by only one person from beginning to end without some others' aiding and proofreading, which goes against the subtitling accuracy. Although the fansub has a strong team in the specific subtitle translation, it only relies on Oday, a somewhat illegal organization, to provide film sources, which lacks the official film import authorization. In addition, its video online upload has a great autonomy without ideological examination. By contrast, in the official system, $\mathrm{CFG}$ is responsible for the film import and distribution, the four film studios are in charge of the purchase of copyright, and SARFT check and edit the film for at least two times, therefore, the content of officially subtitled films is more healthy, green and ideologically in line with China's national conditions.

Besides, from the perspective of operation mode, the official subtitling mode has a strong national nature. Although the four major film studios have been converted into enterprises, their characteristics of state-owned enterprises and monopolizing the economy are still unchanged. On account of its monopoly position, its subtitling mechanism, operating standard and access standard are old-fashioned, which cannot fully adapt to the rapid development of film and TV industry. Conversely, fansub is an open system, and everyone can set up their own fansubs. And the fansub's subtitling is a voluntary and spontaneous act of sharing, so there are few actual economic benefits. Liangliang, the owner of YYets, once said, "The spirit and purpose of the fansub is to be free, to share, to communicate and to learn. Only organizations that have these conditions are fansubs [5]."

\section{B. Comparative Analysis on Subtitling Procedures}

Due to the influence of the official subtitling system, its process of film importing and reviewing are relatively cumbersome, which requires CFG to first submit annual film importing plans and budgets to the State Council and SARFT. Only after their approval can CFG import foreign films which should be firstly examined by SARFT. And then the examined films can be distributed to four film studios. After receiving the film, the studio should sign the copyright contract with the issuer, and then distribute the film to the subtitling and dubbing center, the head of which then assign specific subtitle translation to the subtitle translators. When the subtitle translation is finished, second review should be done by SARFT. In contrast, fansubs are relatively easy to obtain source films which are usually provided by Oday or downloaded by themselves on the network. Once the source film is found and translated by the subtitlers, only one or two revisers proofread the subtitles, and then the film is uploaded on the Internet. Although the reviewing process is contained in both of the two subtitling modes, SARFT is more concern with the ideology of films, while the proofreading team of fansub focuses greatly on the subtitling language and style.

As there is no official channels to get film sources for fansubs, their accessible films lack original subtitles, so they have to dictate the film lines. Therefore, in the subtitling procedure of fansubs, the processes of dictating, consecutive interpreting and timeline making are very necessary, which are not needed in the official film subtitling procedure, because film studios can obtain the detailed specification of original film subtitles from the film issuer after they purchase the copyright.

\section{Problems IN The Two Subtitling Models AND CORRESPONDING SOLUTIONS}

\section{A. Problems in the Two Subtitling Models}

Through comparing and analyzing the two subtitling models, four problems can be induced in both official and web-based models.

Firstly, it is staff lack in the subtitling industry. In the four domestic film studios, the majority of their subtitlers are part time, and August First Film Studio and Beijing Film Studio have shared subtitle translators for a long time. What's more, after the older generation of translators leaving, the younger generation of translators did not completely fill up. As to fansubs, their personnel structures are very loose. Members are all over the world with high mobility, and clustered on BBS rather than in offices.

Secondly, it's the low subtitling payment. According to Wang Jinxi, the reward of an dubbed film is about 50,000 yuan which is shared by all the subtitling participants. This low payment directly leads to the lack of subtitling staff, for 
it is really very hard for the film studios to support such a large number of translators by 50,000 yuan per film. Fansubs are non-profit organizations, so they usually needn't to pay their members, but broadband communications, BBS and server maintenance can cost them as much as 60,000 yuan a year, hence the majority of them have deficits.

The third problem is the low subtitle translator's status. At present, in China, there are no obvious information or signs of translators in the subtitled film or on its promotional posters, and film producers don't care who is the film translator. In the films subtitled by fansubs, although translators' names are displayed, they are net names, not real names. Furthermore, the audience, like the film producer and issuer, aren't concerned with who is the subtitler.

The fourth problem is the non-unified subtitling standards. Each fansub has its own set of subtitling standard and supervising mechanism. Take the usage of punctuation in subtitles for example, some fansubs completely delete punctuation, some completely retain them, some replace them with spaces. This chaotic usage situation severely damages the original aesthetic taste and artistic flavor of the films, and it urgently needs to be standardized and unified [6]. Similarly, each official subtitle translator has his own translating style and principle. In an interview of Jia Xiuyan by journalist Xu Sijian, she said she thought "the fantastic translation style of the fansub will make the movie more attractive[7]", and she hoped to use this style in her film translation.

\section{B. Suggestions to Solve Problems of the Two Models}

It should be said that although official subtitle translation seems "sacred and inviolable" , in fact, like online translation, there is also no clear subtitling standard, and the specific translation practice is extremely uncertain. Furthermore, the official subtitling system is not as complete as the network subtitling system in terms of the overall professional structure. There are not only few actual translators, but also too few overall professionals and professional interactions involved in the translation system. Thus both official subtitling studios and fansubs are confronted with the same above four problems, which are the obstacle to the development of our film industry, so we must propose feasible suggestions to solve these problems.

To solve the problems, we should firstly attach importance to the film subtitling, increase the subtitling cost, and raise the subtitle translators' incomes and their social status; secondly, we ought to make a unified and standard subtitling process, improve the confidentiality system and establish a system of intellectual property protection for film and television translation; thirdly, the government should set up a special department to solve the problems of repeated production, disorderly competition, development restriction and copyright dispute of fansubs[8], and reasonably guide them to promote the international communication of film and television works; lastly, related departments should strengthen the professional training of subtitle translators and improve their translation qualities in order to translate high-qualified films.

\section{SUMMARY}

From the above discussion, it can be seen that the official subtitling system is completely different from that of fansub, the former is a monopolized and strictly managed system, while the latter is an open and well-developed system. In these two systems, the hot discussed official subtitling of Men in Black III is very similar to the YYets' version in terms of the overall translation tendency, and the final audience impression is also roughly similar, but there are many more translating errors in the official edition [9]. This phenomenon is caused by the differences between the two systems. Official subtitlers are paid insufficient attentions, most of them are part-time, both their entry threshold and their income are very low. In addition, they lack professional help, guidance and criticism, and their status is not recognized. In this case, translators lack motivation and professionalism as well as the reviewing process, so the translation quality is relatively low. However, the fansub has improved translator entry mechanism, and professionals are involved in the whole translation process. Although translators have no economic return, they have a certain status and professional recognition. The translator is highly motivated and audited by others, so the translation quality must be higher.

On the whole, although fansubs sometimes may produce higher-qualified film translations than the official studios, their subtitling standard is not so unified as the latter, both of them have problems of staff lack, low subtitling payment, low subtitler's status and non-unified subtitling standards, so they should learn from each other and spare no efforts to solve their problems so as to promote the development of film subtitling in China.

\section{REFERENCES}

[1] Hu zhifeng, Art of TV Communication (in Chinese), Beijing: Beijing University Press, pp. 209, 2004.

[2] Xuan Xihao, Ha mai, From Looking up to Looking down upon: Yesterday and Today of Dubbed Films (in Chinese), [EB/OL], (2012-724) [2018-9-17], http://news.mtime.com/2012/07/24/1493354.htm.

[3] Petergy, Four Fansubs subtitling American TV Series (in Chinese), [EB/OL], (2012-10-31) [2018-9-16], http://www.douban.com/group/ topic/33929185/.

[4] Qian Mengni, The Existential Paradox of the American TV Series Fansub (in Chinese), News World, vol 1, 2011, pp. 93-94.

[5] Anonymous, Fansub, left or right?-An Interview of Liang liang, the Head of YYests, DV @ Times, vol 1, 2010,pp.44-49.

[6] Jiang Xuelong, The Conversion Principle of Punctuation in Chinese Translation of English Film Subtitles (in Chinese), Journal of Lianyungang Technical College, vol 30, 2017, pp. 7-10.

[7] Jiang Siyuan, Subtitle Translation of Man in Black 3 Causing Hot Discussion: Audience-inclination Translation or Over-Translation (in Chinese), [EB/OL], (2012-06-04) [2018-9-18], http:// www. china. com. $\mathrm{cn} /$ info/movies/2012-06/ 04/ content_25556745. htm.

[8] Xie xiuhong, Translator's Adaptation and Selection: A Study on Film and TV Translation (in Chinese), Chengdu: Southern University of Finance \& Economics Press, pp. 29-39, 2017.

[9] Xu Huiru, A Comparative Study on Official and Network-based Subtitling-A Case Study of the Subtitling of Man in Black III, Shanghai: Shanghai International Studies University, pp. 29, 2012. 